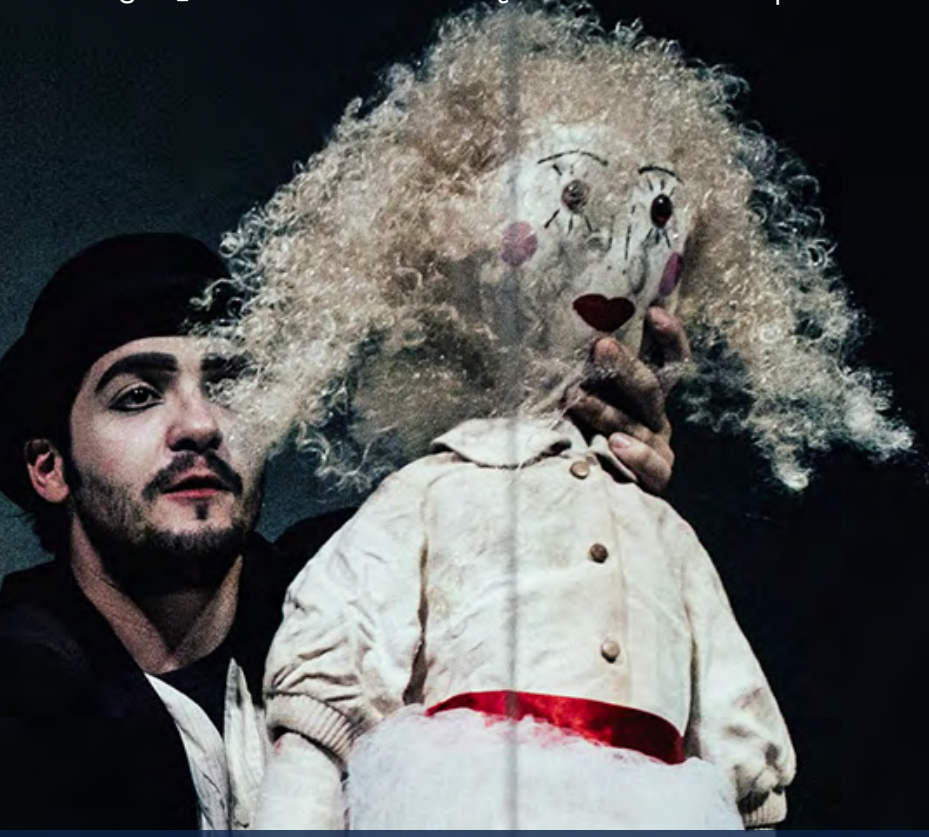

\title{
A moda brasileira é jovem, branca e magra: perfil de estilistas e modelos na SPFW entre 2013 e 2017
}

The Brazilian fashion is young, white, and skinny: profile of stylists and models in SPFW between 2013 and 2017

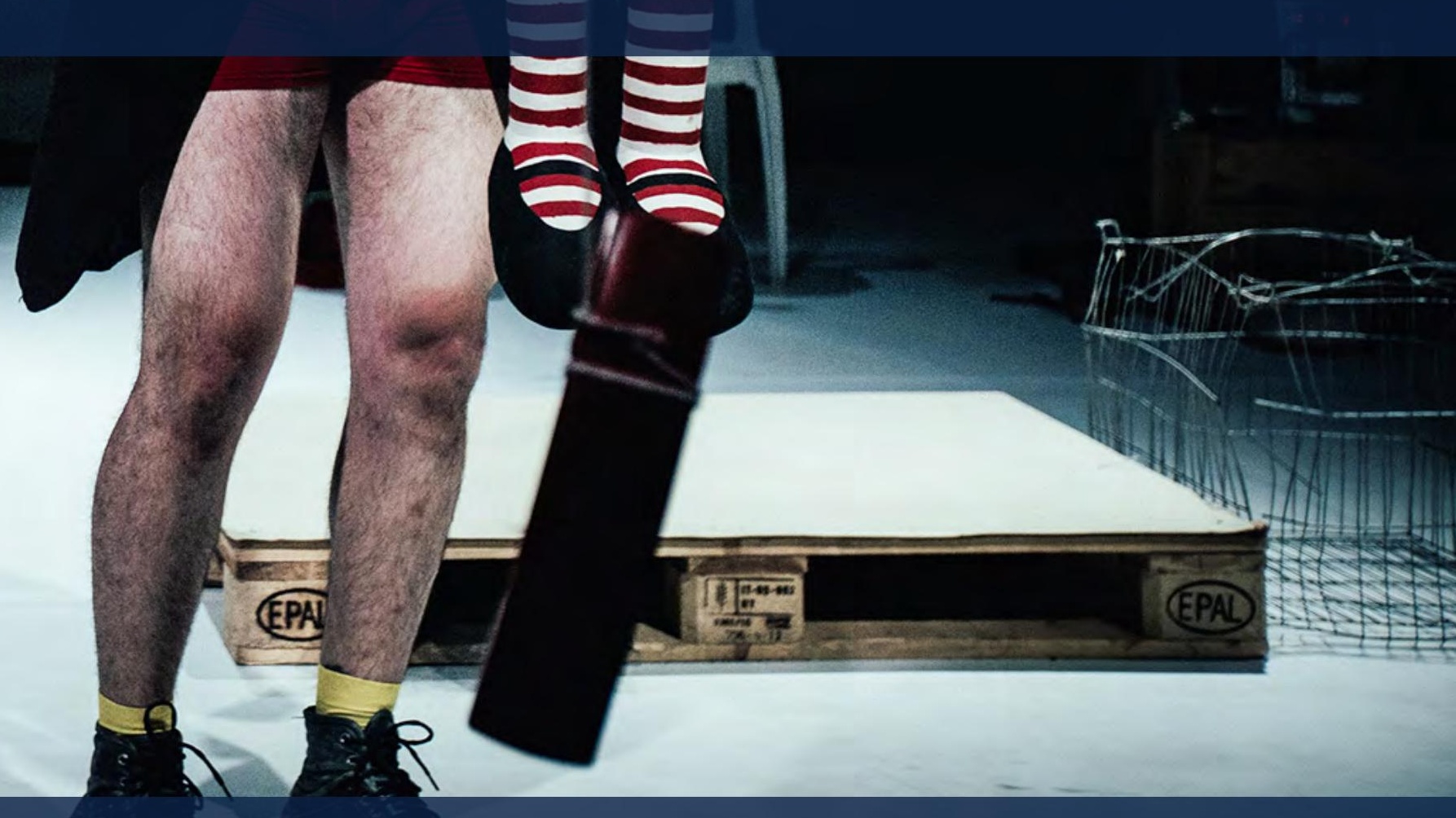

dObra[s] | VOLUME 12 | NÚMERO 26 | AGOSTO 2019 https://dobras.emnuvens.com.br/dobras | e-ISSN 2358-0003 


\section{ANA CAROLINE SIQUEIRA MARTINS ${ }^{1}$}

ORCID: https://orcid.org/0000-0003-1152-913X

\section{CARLA CRISTINA SIQUEIRA MARTINS²}

ORCID: https://orcid.org/0000-0003-1383-1316

[resumo] O corpo, entendido como mídia, linguagem que comunica gostos, possibilidades, continuidades e descontinuidades culturais, foi objeto de estudo para se entender uma das múltiplas vertentes do funcionamento da moda atual. Para tanto, foram investigados os perfis de estilistas e modelos participantes do considerado maior e mais significativo evento de moda do Brasil, o SPFW, entre os anos 2013 e 2017, representativo, portanto, nas dinâmicas e comportamentos atuais do campo da moda com relação a esse tema. A pesquisa se justifica pela importância da moda enquanto fenômeno social, materializado em produtos de consumo que permeiam o corpo e o cotidiano da sociedade, expressando comportamentos, identidades nacionais, regionais, locais, individuais e coletivas, tornando-se instrumento para/nas investigações a respeito das práticas e narrativas culturais. Também pela relevância do setor de moda no país, que possui no eixo de vestuário um papel importante na composição da indústria de transformação nacional, seja em valores da sua produção, seja por sua capacidade de gerar empregos. Por meio da pesquisa bibliográfica e documental e análise dos dados, verificou-se a hegemonia jovem/adulta, branca e magra dos biótipos dos agentes investigados, que assim representam a moda brasileira para o país e para mundo. Entre os autores que ofereceram suporte para as análises destacam-se Bourdieu (1992, 1996, 2001, 2006), Del Priore (2000), Mesquita e Castilho (2012) e Santaella (2004).

\section{[palavras-chave] Moda brasileira. Corpo. Juventude. Magreza. Branquitude.}

\footnotetext{
1 Mestre. Universidade Estadual de Maringá.

E-mail: lf_carol@hotmail.com. Lattes: http://lattes.cnpq.br/8912956416859713.

2 Mestre. Universidade Estadual de Maringá.

E-mail: carlasiq10@gmail.com. Lattes: http://lattes.cnpq.br/9572279239008148.
} 
[abstract] The body, understood as a medium and as a language which communicates personal tastes, possibilities, as well as cultural continuities and discontinuities, was employed in this article as a study object directed towards the understanding of one among the multiple strands of the workings of current fashion. In order to achieve said goal, a profile investigation of the stylists and participants of that which is considered the greatest and most significant fashion event in Brazil, namely, SPFW, was carried out, with a special focus on the period between the years of 2013 and 2017. Such a time lapse is, therefore, representative of the current dynamics and behaviors of the fashion field regarding this theme. This research is justified by the importance of fashion as a social phenomenon which is materialized in consumer goods which permeate society's entirety and daily life. It expresses behaviors and national, regional, local, individual and collective identities, becoming an instrument both for and in the investigations about cultural practices and narratives. The justification also comes from the relevance of the fashion segment in Brazil, which plays in the apparel axis an important part in the composition of the national transformation industry, whether because of the monetary worth of its manufacturing or its capacity for job creation. By means of bibliographical and documental research and data analysis, a hegemony of young/adult, white and thin biotypes was verified in the investigated subjects, who therefore represent Brazilian fashion in this way for the country itself and for the rest of the world. Among the authors who provided support for the analysis, some worthy of mention are Bourdieu (1996, 2001, 2006), Del Priori (2000), Mesquita and Castilho (2012), and Santaella (2004).

[keywords] Brazilian fashion. Body. Youth. Thinness. Whiteness.

Recebido em: 15-03-2019.

Aprovado em: 15-05-2019. 


\section{Introdução}

A moda enquanto fenômeno histórico-social, expressivo de um determinado tempo e espaço e das relações socioculturais engendradas nele, apresenta-se como terreno fértil para as interpretações de suas narrativas, entre elas as que envolvem o corpo, este que está presente em todas as ações dos agentes em uma sociedade, de forma potencializada ou não, e que aqui será privilegiado. Neste artigo, o corpo foi entendido como mecanismo de suporte e ação por meio do qual são concebidas e manifestadas as propostas criativas de moda e, logo, interesses, preferências e práticas culturais.

A escolha do lócus de estudo - a SPFW, São Paulo Fashion Week, em português Semana de Moda de São Paulo - se apresentou pertinente, devido à sua relevância para o estabelecimento e desenvolvimento da moda nacional. Criado na década de 1990, o evento SPFW é um marco importante na busca dos envolvidos com o setor da moda por sua consolidação (em trânsito). E, atualmente, é considerado o maior do Brasil e América Latina e o quinto mais importante do mundo, junto com as também reconhecidas semanas das capitais da moda, Paris, Londres, Milão e Nova Iorque, apresentando-se assim como palco para expressão e difusão da moda brasileira para o país e mundo (CAMELO; COELHO-COSTA, 2016).

O SPFW, ao expor/desfilar novas propostas e tendências de moda de uma parcela dos criadores brasileiros, atua como uma mídia que influencia comportamentos, padrões estéticos e construções de identidades individuais e/ou coletivas, possibilidades e estruturas de funcionamento da moda no Brasil. Quando foi criado, era realizado com quatro desfiles por dia e público de 300 pessoas. Já no ano de 2014, por exemplo, a Semana de Moda de São Paulo reuniu em torno de 100 mil pessoas em seus 7 dias de duração. De acordo com o colunista Pedro Diniz, do jornal Folha de São Paulo, "a cada edição, nos últimos seis anos, o evento gerou R\$ 2 bilhões em negócios e 11 mil empregos diretos e indiretos" (DINIZ, 2014). Esses dados deixam claro a proeminência do evento como expressão de identidade da moda nacional e, sendo assim, sua relevância como objeto de pesquisas e análises diversas (CHLAMTAC, 2015).

0 intuito deste texto foi pesquisar e analisar as expressões de corpos presentes no evento $S P F W$, e assim compreender qual cânone corpóreo é apresentado e valorizado pela moda nacional, utilizando para tal duas categorias-base: o perfil de estilistas e o perfil de modelos participantes entre os anos 2013 e 2017. Os(as) estilistas foram selecionados(as) por serem um dos agentes de poder do contexto estudado e, por isso, é relevante investigar sobre suas características (gênero, cor, idade e perfil de corpo), além de suas escolhas com relação aos corpos/modelos que desfilaram suas criações nas passarelas do evento. As escolhas dos(as) estilistas, junto com diretores de marcas, produtores de moda, stylists etc. revelaram suas preferências quanto ao perfil de corpos reconhecidos como oportunos para representar a moda ali apresentada.

Metodologicamente, a pesquisa bibliográfica e a documental foram privilegiadas, concentrando-se nas aparições de estilistas e modelos nos desfiles da SPFW de 2013 a 2017, refletindo sobre qual corpo apareceu e foi reforçado pelas escolhas de marcas e estilistas que participaram e participam do evento e dão credibilidade, pelo seu poder influenciador, a um ideal a ser seguido. 
Na pesquisa documental utilizou-se como fonte principal a plataforma online de conteúdo oficial do SPFW chamada FFW, na qual foi possível explorar as imagens e textos de todas as edições do evento ocorridas no período estudado, totalizando 10 edições e 329 desfiles. 0 site FFW é organizado por abas de conteúdo divididas em: "Home", "Desfiles", "Notícias", “Moda”, “Beleza”, “Trends” (tendências), "Life Style” (estilo de vida), "Blog”, "Vídeos", "Models" (modelos) e "Tudo". Ainda, abas específicas intituladas: "SPFW", que trata especificamente sobre o evento; "FFWMAG", que apresenta o conteúdo produzido na Revista FFW, e "FASHION TOUR", que divulga a respeito deste projeto. Para o estudo, foram consultadas na aba "SPFW", categoria "Temporada”, as edições 35 a $44^{3}$. As pesquisas nesse meio digital foram realizadas entre agosto e dezembro de 2017 e contemplaram principalmente os textos imagéticos, totalizando aproximadamente 10.998 páginas de fontes analisadas. Dessas análises foram produzidos relatórios de cada edição, já voltados para a perspectiva deste estudo.

A pesquisa se justifica pela importância da moda enquanto fenômeno social, materializado em produtos de consumo que permeiam o corpo e o cotidiano da sociedade, expressando comportamentos, identidades nacionais, regionais, locais, individuais e coletivas, tornando-se instrumento protuberante nas investigações a respeito das práticas e narrativas culturais, por exemplo. Também pela relevância do setor de moda no país, que possui no eixo de vestuário um papel importante na composição da indústria de transformação nacional, seja em valores da sua produção, seja por sua capacidade de gerar empregos. 0 dado mais recente encontrado sobre esse assunto, de 2012, apontou que a produção nacional de artigos de vestuário chegou a 6,1 bilhões de peças. Em valores monetários, o setor produziu em 2012 um total de US $\$$ 45,5 bilhões, o que é equivalente a 4,3\% do valor total da produção da indústria brasileira de transformação. Os empregos gerados somaram 1,2 milhão de postos de trabalho, demonstrando assim sua relevância econômica e seu forte impacto social (IEMI, 2013).

\footnotetext{
3 Referências das páginas do site FFW consultadas para análise do perfil de estilistas e modelos: FASHION FORWARD. Desfiles. 2013a. Disponível em: http://ffw.uol.com.br/desfiles/sao-paulo/verao-2014-rtw. Acesso em: 22 ago. 2017

FASHION FORWARD. Desfiles. 2013b. Disponível em: http://ffw.uol.com.br/desfiles/sao-paulo/inverno-2014-rtw/. Acesso em: 29 ago. 2017.

SPFW - São Paulo Fashion Week. Verão 2015 RTW. 2014a. Disponível em: http://ffw.uol.com.br/spfw/ verao-2015-rtw/. Acesso em: 15 set. 2017.

SPFW - São Paulo Fashion Week. Inverno 2015 RTW. 2014b. Disponível em: https://ffw.uol.com.br/spfw/ inverno-2015-rtw/. Acesso em: 28 set. 2017.

SPFW - São Paulo Fashion Week. Verão 2016 RTW. 2015a. Disponível em: https://ffw.uol.com.br/spfw/ verao-2016-rtw/. Acesso em: 10 out. 2017.

SPFW - São Paulo Fashion Week. Inverno 2016 RTW. 2015b. Disponível em: https://ffw.uol.com.br/spfw/ inverno-2016-rtw/. Acesso em: 23 out. 2017.

SPFW - São Paulo Fashion Week. N41. 2016a. Disponível em: https://ffw.uol.com.br/spfw/verao-2017-rtw/. Acesso em: 3 nov. 2017.

SPFW - São Paulo Fashion Week. N42. 2016b. Disponível em: http://ffw.uol.com.br/spfw/n42/. Acesso em: 18 nov. 2017.

SPFW - São Paulo Fashion Week. N43. 2017a. Disponível em: http://ffw.uol.com.br/spfw/n43/. Acesso em: 3 dez. 2017

SPFW - São Paulo Fashion Week. N44. 2017b. Disponível em: http://ffw.uol.com.br/spfw/n44/. Acesso em: 20 dez. 2017.
} 
Como um sistema de signos, a moda difunde conceitos por meio dos quais o ser humano esquematiza a sua posição no mundo e a sua relação com ele (BARNARD, 2003). Ainda, a moda e seu funcionamento constroem territórios de sentido sobre as possibilidades, constâncias, dinâmicas e movimentos a respeito dela, onde o corpo é veículo para suas exposições e entendimentos. Corpo e moda se apresentam como linguagem, em um ritual comunicativo que influencia seus interlocutores à medida que esses se envolvem com suas expressões e ditames, manifestados de maneira estética.

As estéticas de moda apresentadas no evento SPFW comunicaram maneiras de ser da moda brasileira, em especial aqui, no que diz respeito ao corpo, ao que é recorrente nas aparições. Atualmente com 22 anos de existência, o SPFW apresenta duas edições anuais, uma de Outono-Inverno e outra Primavera-Verão, que expõem não só as criações de marcas e estilistas de moda como também aspectos culturais riquíssimos para se pensar o campo ${ }^{4}$ da moda.

As localidades oficiais do evento nos anos pesquisados foram o Pavilhão da Bienal do Ibirapuera, o Anfiteatro do Parque Villa-Lobos e Parque Candido Portinari, todos na cidade de São Paulo. 0 acesso ao evento era restrito a convidados, geralmente profissionais envolvidos com a área de moda como estilistas, modelos, celebridades, produtores de moda, jornalistas, lojistas e consumidores das grifes participantes da edição. Todavia, desde o ano 2001, o evento passou a ter transmissão online ao vivo, por meio da Plataforma FFW e do portal Terra, por meio dos quais todos os interessados, além de terem acesso em tempo real aos desfiles, podiam conhecer sobre o funcionamento dos bastidores e corredores do evento e acompanhar comentários de estilistas, jornalistas e personalidade sobre as criações apresentadas, via conteúdo veiculado na SPFW TV, produzida especialmente para cobertura do evento, o que permitia tanto maior acesso como maior impacto influenciador (GUERATO, 2010; CADDAH, 2012).

A FFW é uma plataforma digital de conteúdo voltado para moda e cultura, lançada pela promotora de eventos Luminosidade em 2009, de propriedade de Paulo Borges, empresário e produtor de eventos que idealizou o SPFW. A plataforma publica conteúdos de todas as edições a partir do ano 2000 até o presente momento. Com o intuito de substituir o antigo portal $S P F W$, a $F F W$ se tornou referência para o calendário da moda brasileira. 0 conteúdo se destaca por ter o maior acervo brasileiro de fotos de desfiles nacionais e internacionais. 0 portal foi o primeiro site de moda no Brasil a explorar a convergência de textos, fotos, áudios e vídeos, por isso a sua escolha como fonte principal de pesquisa (FASHION FORWARD, 2018).

Como citado anteriormente, para o desenvolvimento da pesquisa foram estabelecidas categorias-base distintas - o perfil de estilistas e o perfil de modelos participantes do evento SPFW entre os anos 2013 e 2017 -, e foram elaborados relatórios para cada vertente

\footnotetext{
${ }^{4}$ A denominação campo nesse texto considerou a teoria de Pierre Bourdieu. 0 campo consiste em um espaço de lutas onde ocorrem as relações e disputas entre os agentes, grupos e estruturas sociais: "[...] os campos não são estruturas fixas. São produtos da história das suas posições constitutivas e das disposições que elas privilegiam” (BOURDIEU, 2001, p. 129).
} 
investigativa. Nas análises sobre os(as) estilistas, foram contempladas as categorias gênero, cor, idade e perfil corporal dos(as) criadores(as) de moda citados nos textos e/ou presentes em cada desfile investigado. Primeiramente, foi realizada uma listagem de todos os nomes dos(as) profissionais participantes da Semana nos cinco anos de estudo, o que derivou no resultado de 122 estilistas. Em seguida, foram pesquisadas, no próprio portal $F F W$ e em demais veículos de mídia que fizeram a cobertura do evento, matérias e entrevistas com estilistas para que assim fossem identificadas as características pretendidas, principalmente com relação à idade. Vale destacar que uma pequena parcela de estilistas não possuía todas as informações disponíveis nos meios escolhidos para a investigação, por isso, estes foram contatados via e-mail e redes sociais digitais particulares. Assim, a pesquisa alcançou a completude dos dados almejados.

Já para a pesquisa referente ao gênero, cor e perfil corporal de modelos participantes do evento, todos os dados foram coletados na plataforma FFW.

A nomenclatura para o perfil de cor considerou a norma instituída pelo IBGE (Instituto Brasileiro de Geografia e Estatística), que nomeia as cores branco, preto, pardo, amarelo e indígena para se referir à coloração de pele da população brasileira.

Para análise do perfil corpóreo, divido entre as categorias corpo magro, mediano e gordo, utilizou-se como referência as definições cunhadas pelo fisiologista norte-americano William Herbert Sheldon, referente às características físicas que assim foram classificadas em três tipos: ectomorfo, mesomorfo e endomorformo. De acordo com essas definições, o corpo ectomorfo é esguio e magro, pois predominam os ossos sobre o tecido adiposo e os músculos, uma estrutura óssea estreita, com ombros mais curtos, cintura fina e caixa torácica estreita, conferido uma forma corporal retangular. As pernas são mais alongadas e magras e a largura do corpo reduzida. Já o perfil mesomorfo (definido aqui como biótipo mediano, pois se encontra entre os perfis ectomorfo e endomorfo) tem uma estrutura óssea grande, músculos mais fortes e definidos; forma corporal trapézio, possuindo certa facilidade em acumular gordura em algumas partes do corpo, como no abdômen. E, por fim, as pessoas de perfil endomorfo, geralmente consideradas gordas, que possuem maior quantidade de tecido adiposo em relação aos músculos e ossos, adquirem gordura facilmente, tendo aspecto corporal mais flácido que os demais, forma corporal arredondada e dificuldade para adquirir músculos (KISS, 1987; SABINO, 2017).

\section{O corpo da/na moda na SPFW}

Nas análises dos dados coletados, inicialmente foram tabuladas as características dos(as) estilistas. Nelas, no que concerne ao gênero, os resultados apontaram que a presença de estilistas mulheres foi maior (59\%), embora a masculina tenha sido significativa (41\%), demonstrando um aparente equilíbrio com relação às oportunidades de participação no evento no que se refere ao gênero. Todavia, se for analisado que no ensino superior em moda se formam majoritariamente mulheres e que, culturalmente, ao gênero femini- 
no é mais frequentemente atribuído o interesse em assuntos relacionado à moda (ALÁRIO, 2007), os percentuais revelaram uma disparidade e predileção à participação de estilistas homens. Mesmo assim, é importante salientar que esse cenário é bem diferente do apresentado nos anos 1960-1970, início da configuração de um campo da moda no Brasil, em que, segundo Bonadio (2014), a figura criativa da moda nacional era majoritariamente masculina. Isso demonstra avanço no que diz respeito à presença feminina em posições privilegiadas no campo da moda, consequência, sem dúvida, de movimentos, políticas e conquistas das mulheres na segunda metade do século XX.

Quanto à cor e ao perfil corporal, manteve-se a feição branco e magro, recorrente tanto nos croquis e escolhas de modelos, quanto na própria estrutura corpórea dos(as) estilistas.

De todos(as) estilistas participantes, 75,4\% eram brancos e 67,2\% magros, em que a magreza recaiu mais entre as mulheres, que representaram $61 \%$ do total, dados que relatam preferências, continuidades e imposições implícitas e explicitas de boa parte do sistema da moda que, como já apontava Barthes (2009), expressa-se também no imperativo do rigor, estruturada em condutas estruturantes bastante enraizadas, do ponto de vista de Bourdieu (2006). Embora, ambos os autores tenham teorizado práticas de moda ocorridas especialmente na França dos anos 1960, a força condicionante desse habitus reverberou em muitos outros países e por várias décadas posteriores. Habitus são "os princípios geradores das práticas distintas e distintivas dos agentes em um determinado campo" social, de modo que estes se comportam condicionados a uma estrutura de conduta já incorporada pelo contexto, percebida como comum/habitual (BOURDIEU, 1996, p. 22).

Na moda, essa força condicionante se deve, por exemplo, ao fato de a França, desde o século XIX, ser considerada o berço da moda e, por isso, suas propostas de moda terem forte adesão em outras partes do mundo. No Brasil, tal influência se intensifica pela história de colonização do país por países europeus, que de forma enfática impuseram modos estrangeiros ao vestuário e, posteriormente, à moda nacional, que pela ação de seus agentes conservou tal prática de copiar modelos e condutas vindos de fora do país (BRAGA; PRADO, 2011).

Sob esse aspecto, o corpo do(da) estilista brasileiro(a) pode ser considerado tanto imperativo, aquele que cria e seleciona os perfis corpóreos que desfilarão suas coleções, quanto dominado, à medida em que é configurado e reconfigurado conforme os ditames percebidos como valorosos em seu contexto. Isto é, o habitus que estabelece as condutas deste microcosmo social é conservado, pois o(a) estilista (agente com capital simbólico de poder) é tanto estruturante como estruturado pelas forças culturais marcadoras dessa estética hegemônica, que ainda no século XXI insiste em reproduzir aparência europeia.

No Brasil, até a segunda metade do século XX, grande parte da conduta de moda adotada no país era incorporada da Europa (o que, em menor dimensão, permanece nos dias atuais), por meio da reprodução de usos e maneiras inicialmente trazidos pelos colonizadores e, depois, pela vinda da corte portuguesa ao país, no século XIX, fazendo com que a família real exercesse papel importante na moda que os brasileiros adotavam, influenciando a permanência e fortalecimento de representações estrangeiras em terras tropicais. 
As modas e os modos seguidos também eram difundidos pelas revistas e folhetins de moda da época, que estabeleciam todo um código vestimentar e de moda a ser seguido e copiado, o que incluía o corpo. Nesse período, os produtos de moda (acessórios, sapatos, meias, roupas, espartilhos, maquiagem) e imagens de referência quanto à beleza eram importados da considerada capital da moda - Paris - e chegavam ao Brasil via encomenda ou trazidos de navio para assim atenderem à elite, enquanto os menos favorecidos copiavam e reproduziam as vestimentas usadas por ela. Homens e mulheres, em busca de status e do que consideravam como elegante, refletiam os modos e costumes dos europeus que, no caso do corpo, privilegiavam o biótipo magro (BRAGA; PRADO, 2011).

0 estereótipo do corpo magro se torna paradigma no campo da moda, convertendo-se em agente dominante. Assim, estilistas incorporaram esse biótipo (67,2\% dos(as) estilistas participantes da SPFW eram magros) como forma de serem pertencentes, em alguma medida, a esse modelo. Se o(a) estilista pode ser percebido(a) como agente decisivo dos padrões e corpos da moda, sua seleção de corpo indicava um arquétipo por ele(a) considerado valoroso. Sendo assim, ele(a), entendendo-se como também representante dessa estética, visava ter ou se aproximar do ideal de corpo privilegiado em suas escolhas.

Mesmo o habitus sendo um mecanismo condicionado e condicionante das práticas sociais, ele não está fechado, resistente às mudanças, pois são os agentes, de acordo com seus interesses e de posse de posições privilegiadas que permitem articulação em determinado campo social, que implicarão em suas transformações ou permanências. "O habitus não é destino como se vê às vezes. Sendo produto da história, é um sistema de disposição aberto, que é incessantemente confrontado por experiências novas e assim incessantemente afetado por elas" (BOURDIEU,1992, p. 108). Nessa tangente, cabe ressaltar que a conservação de práticas não é algo obrigatório, mas sim uma estratégia de agentes para se posicionarem no campo que atuam, por reconhecerem que tais posicionamentos lhes conferem capital simbólico e status positivo.

Ainda sobre o assunto corpo, a idade foi outra característica analisada, em que foram elencadas 4 subcategorias, que derivaram os seguintes resultados: 56,6\% dos(as) estilistas possuíam de 31 a 45 anos de idade; 30,3\% de 46 a 60 anos; 7,4\% de 22 a 30 anos, e 5,7\% acima de 60 anos. Sendo assim, foi verificado que os(as) criadores(as) de moda do evento pertenciam à fase etária adulta, totalizando 86,9\% deles(as), enquanto os extremos de idade contemplados apresentaram percentuais menores. Para a divisão das subcategorias de idade foram observadas as definições estabelecidas pelo Estatuto da Criança e do Adolescente (Lei no 8.069, de 13 de julho de 1990), que considera o fim da adolescência aos 18 anos e o início da fase adulta jovem entre 18 e 21 anos, e o Estatuto do Idoso (Lei no 10.741, de 1 de outubro de 2003), que define a pessoa idosa como aquela que tem 60 anos ou mais (BRASIL,1990; BRASIL, 2003).

O conjunto de informações sobre gênero, cor, idade e perfil corporal dos(as) estilistas está representado no quadro 1 a seguir. 
QUADRO 1 - PERFIL DE ESTILISTAS PARTICIPANTES DA SPFW ENTRE 2013 E 2017 GÊNERO, COR, IDADE E PERFIL CORPÓREO.

\begin{tabular}{|c|c|c|c|}
\hline GÊNERO & COR & IDADE & PERFIL CORPÓREO \\
\hline $\begin{array}{l}59 \% \text { feminino } \\
(72 \text { mulheres })\end{array}$ & $\begin{array}{l}75,4 \% \text { brancos(as) } \\
\text { ( } 59 \text { mulheres e } 32 \text { homens) }\end{array}$ & $\begin{array}{l}7,4 \% \text { ( } 22 \text { a } 30 \text { anos) } \\
\text { ( } 5 \text { mulheres e } 5 \text { homens) }\end{array}$ & $\begin{array}{l}67,2 \% \text { magro(a) } \\
\text { (50 mulheres e } 32 \text { homens) }\end{array}$ \\
\hline $\begin{array}{l}41 \% \text { masculino } \\
\text { ( } 50 \text { homens) }\end{array}$ & $\begin{array}{l}18,2 \% \text { pardos(as) } \\
\text { ( } 5 \text { mulheres e } 17 \text { homens) }\end{array}$ & $\begin{array}{l}56,6 \% \text { ( } 31 \text { a } 45 \text { anos) } \\
\text { ( } 40 \text { mulheres e } 28 \text { homens) }\end{array}$ & $\begin{array}{l}23 \% \text { mediano(a) } \\
(15 \text { mulheres e } 13 \text { homens })\end{array}$ \\
\hline & $\begin{array}{l}\text { 4\% amarelos(as) } \\
\text { ( } 4 \text { mulheres e } 1 \text { homem) }\end{array}$ & $\begin{array}{l}30,3 \% \text { ( } 46 \text { a } 60 \text { anos) } \\
\text { ( } 21 \text { mulheres e } 16 \text { homens) }\end{array}$ & $\begin{array}{l}9,8 \% \text { mediano }(a) \text { para gordo(a) } \\
\text { ( } 4 \text { mulheres e } 8 \text { homens) }\end{array}$ \\
\hline & $\begin{array}{l}2,4 \% \text { pretos(as) } \\
\text { (1 mulher e } 2 \text { homens) }\end{array}$ & $\begin{array}{l}5,7 \% \text { (acima } 60 \text { anos) ( } 4 \text { mulheres e } \\
3 \text { homens) }\end{array}$ & $0 \%$ gordo $(\mathrm{a})$ \\
\hline & $0 \%$ indígena & & \\
\hline
\end{tabular}

FONTE: As autoras, 2017, com base nas referências indicadas na nota 3.

Os dados apresentados no quadro 1 fazem ressoar a recusa/resistência do campo da moda (aqui interpretado pelas características de estilistas do São Paulo Fashion Week) ao biótipo gordo, negro e de terceira idade, em contrapartida à presença significativa de pessoas brancas, magras, jovens ou adultas na composição do grupo de estilistas que participavam do evento. Isso porque a ausência de pessoas com esse perfil nos cargos de estilo aqui analisados não pode ser justificada pela composição populacional do Brasil, já que, de acordo com pesquisa realizada pelo Ministério da Saúde em 2015, "o índice de brasileiros acima do peso segue em crescimento no país - mais da metade de população está nesta categoria (52,5\%) e destes, 17,9\% são obesos"' (FORMIGA, 2015).

Ainda conforme dados do IBGE, entre os anos 2012 e 2016 44,2\% dos brasileiros(as) se autodeclararam brancos(as), enquanto 46,7\% e 8,2\% pardos(as) e pretos(as) respectivamente, e as pessoas com 60 anos ou mais representaram 14,4\% da população (PNAD, 2017), evidências que confirmam a situação de minoria social dessas pessoas no espaço estudado.

0 quadro percentual dos grupos observados enfatiza a questão da minoria social, porque esta não diz respeito a uma minoria estatística, de uma parte menos numerosa da população, mas de inferioridade com relação a posição social, de possibilidades e oportunidades de entrada e pertencimento a um contexto que, no caso estudado, refere-se à minoria de corpos diversos, fora do padrão, no campo da moda. Assim, considerando que os biótipos pertencentes à minoria social aqui abordada possuíam menos poder que os entendidos como ideais (jovem, branco e magro), as escolhas estratégicas dos(as) estilistas sinalizavam os valores deste grupo, fato que reverberou nas escolhas dos corpos de modelos que representaram suas criações, como descrito a seguir. 
Para as análises do perfil dos(as) modelos que desfilaram na São Paulo Fashion Week no período pesquisado, foram verificadas 10.936 páginas online, nas quais eram expostos(as) modelos desfilando nas apresentações das coleções correspondentes às 10 edições investigadas. Foi elaborada uma tabela específica para compreensão de qual biótipo foi privilegiado no evento, de acordo com as categorias ano do evento, marca desfilada e quantidade de looks desfilados por marca, pois a análise focou nas aparições de looks desfilados por modelos e não na quantidade de modelos, visto que era comum a repetição desses(as) profissionais durante o desfile.

No momento de caracterização dos perfis dos(as) modelos ocorreram dificuldades na categoria cor, em especial na distinção entre as cores branco e pardo, por conta das interferências de maquiagem, máscaras, roupas sobre rosto e corpo, além dos efeitos de iluminação que comprometeram o reconhecimento. Deste modo, para a categoria cor foram unificadas as cores branco e pardo em uma só categoria designada: "branco ou pardo", além das cores preto, amarelo (de origem nipônica) e vermelho (de origem indígena). E, na categoria perfil corporal, foram verificados a quantidade de looks desfilados por corpos altos e magros, definidos aqui como o padrão de corpo contemplado nas manifestações de moda, e de biótipos fora desse padrão (em que em termos de corpo, para esse artigo privilegiou-se o perfil mediano e gordo).

A categoria idade também foi verificada e por meio dela foi analisada a quantidade de looks desfilados por modelos jovens ou adultos(as) com idade de 18 a 45 anos, e modelos acima de 46 anos, intitulados(as) como adultos/maduros(as) ou de terceira idade, usando para tal as mesmas diretrizes adotadas anteriormente para a verificação do perfil de estilistas.

No primeiro ano de análise, 2013, houve 55 marcas participantes, que totalizaram 1.753 looks desfilados, isto é, 1.753 aparições de modelos nas passarelas do evento. Destes(as), 1672 eram de cor branca ou parda (95,3\%), 73 modelos de cor preta $(4,2 \%)$ e 8 de cor amarela (0,5\%). Quanto ao perfil de corpo desfilado neste ano, $100 \%$ corresponderam ao biótipo magro e jovem/adulto(a).

Já no ano 2014, 70 grifes desfilaram suas coleções, somando 2.344 modelos exibidos(as), em que 2133 aparições foram de modelos brancos(as) ou pardos(as) (91\%), 207 de cor preta (8,8\%) e 4 de cor amarela (0,2\%), apresentando um aumento de mais de $50 \%$ da presença de corpos negros em comparação ao ano anterior. Referente ao perfil corpóreo, as manifestações permaneceram as mesmas, isto é, nenhum(a) modelo diferente do biótipo magro desfilou no evento, e quanto à categoria idade, $100 \%$ eram jovens ou adultos(as).

0 ano de 2015, que teve 70 marcas desfiladas entre as edições de Primavera/Verão 2016 e Outono/Inverno 2016, houve uma maior diversidade de corpos nas passarelas, embora ainda pouco expressiva. Isso porque dos/das 2.355 modelos do casting, 212 eram negros(as), correspondendo a 9\%, 13 eram de cor amarela (0,6\%) e 2.130 eram de cor branca ou parda $(90,4 \%)$. E nas categorias perfil de corpos e idade, houve 1 modelo com biótipo gordo $(0,04 \%)$ dentre os(as) 2354 modelos magras(os) (99,96\%), e 8 modelos adultos(as) maduros(as) ou de terceira idade $(0,3 \%)$ em relação aos demais 2.347 que participaram $(99,7 \%)$.

Em 2016, algumas propostas se destacaram no que diz respeito a tipos de corpos desfilados. A marca FH, do estilista Fause Haten, apresentou bonecas brancas no lugar de modelos, e o estilista Ronaldo Fraga escolheu 1 mulher e 4 homens refugiados de guerra que 
residiam no Brasil para compor os desfiles da edição Primavera/Verão 2017, e mulheres transgêneras para representarem todo seu grupo de 32 modelos na edição de Outono/Inverno 2017. A marca estreante, LAB, escolheu 70\% de modelos negras(os) para seu desfile. Neste ano, 62 marcas estiveram presentes na São Paulo Fashion Week e 2.178 looks foram desfilados, sendo 1.905 por modelos brancos(as) ou pardos(as), correspondendo a 87,4\% dos(as) profissionais participantes, 266 de cor preta $(11,9 \%)$ e 7 de cor amarela $(0,4 \%)$. Na categoria corpo, 2.156 pessoas apresentaram perfil magro (99\%), 19 modelos biótipo mediano $(0,9 \%)$ e 3 modelos corpos gordos $(0,1 \%)$. Na análise da idade, a maioria de jovens ou adultos prevaleceu - 2177 modelos -, correspondendo a 99,96\% do total, enquanto apenas 1 modelo era pertencente à terceira idade $(0,04 \%)$.

No último ano de investigação, 2017, foi reiterada a permanência de corpos que vem sendo reforçada pelas escolhas de marcas e estilistas que participaram do evento, ainda que com o maior percentual de modelos fora do padrão de cor, corpo e idade dos cinco anos investigados. Em 2017, 78 grifes participaram, totalizando 2.306 aparições de modelos. Houve a presença de 327 modelos pretos desfilando (14,2\%), 5 de cor amarela (0,2\%) e a grande maioria, 1974, de cor branca ou parda (85,6\%). 0 predomínio de corpos magros também foi reincidente, sendo que 2267 modelos $(98,4 \%)$ tinham esse perfil, seguido de 29 pessoas com corpos medianos (1,2\%) e 10 com corpos gordos (0,4\%). Quanto à idade, 2306 modelos (99\%) eram jovens/adultos(as), em detrimento da idade adulta/madura ou terceira idade, que mesmo com o maior número, 25 pessoas, representou 1\% das participações.

Sobre o ano de 2017, é importante salientar que nas duas edições da SPFW foi possível notar uma incipiente diversificação de corpos; foram verificados, além dos 10 modelos gordos(as) e 25 pessoas com perfil de idade adulto/maduro(a) ou terceira idade, 2 modelos com alguma deficiência corporal, 2 com vitiligo (doença caracterizada, segundo Bruna (2018), pela diminuição ou falta de melanina em determinadas áreas do corpo, gerando manchas brancas nos locais afetados), 92 com tatuagens e/ou piercings, 25 aparições de modelos do sexo feminino com cabelos raspados e 9 mulheres transgêneras. Ou seja, estéticas pouco visualizadas nos desfiles de moda do evento, que assim eram apresentadas como novidade, atributo importante para lançamentos de moda, além de serem congruentes com movimentos em prol da "representatividade" que emergia no período e, por isso, influía numa percepção positiva de consumidores e demais agentes de poder da moda.

0 conceito de representatividade, seja na moda ou em outras esferas culturais, era assunto tratado por diversos meios de comunicação. As reivindicações de parte da sociedade, refletidas em posturas de consumidores que discutiam o tema, passaram a pressionar, de variadas formas, condutas que contemplassem a multiplicidade e heterogeneidade das manifestações e possibilidades sociais que vieram à tona nesse período, entre elas a representatividade étnica, corpórea, sexual e de gênero, fato que passou a influir, mesmo que de forma incipiente, nas expressões de moda de alguns estilistas da SPFW.

Os quadros 2, 3 e 4 demonstram de forma clara a caracterização realizada sobre as aparições de modelos no maior evento brasileiro de moda, nos anos de 2013 a 2017. 
QUADRO 2 - PERFIL DE MODELOS PARTICIPANTES DA SPFW ENTRE 2013 E 2017- COR

\begin{tabular}{|l|c|c|c|c|c|}
\hline \multicolumn{1}{|c|}{ ANO/RESULTADOS } & 2013 & 2014 & 2015 & 2016 & 2017 \\
\hline $\begin{array}{l}\text { \% de modelos de cor } \\
\text { branca ou parda }\end{array}$ & $95,3 \%$ & $91 \%$ & $90,4 \%$ & $87,4 \%$ & $85,6 \%$ \\
\hline $\begin{array}{l}\% \text { de modelos de cor preta } \\
\text { \% de modelos de cor }\end{array}$ & $4,2 \%$ & $8,8 \%$ & $9 \%$ & $12,2 \%$ & $14,2 \%$ \\
\hline $\begin{array}{l}\text { \%marela de modelos de cor } \\
\text { vermelha }\end{array}$ & $0,5 \%$ & $0,2 \%$ & $0,6 \%$ & $0,4 \%$ & $0,2 \%$ \\
\hline
\end{tabular}

FONTE: As autoras, 2017, com base nas referências indicadas na nota 3.

QUADRO 3 - PERFIL DE MODELOS PARTICIPANTES DA SPFW ENTRE 2013 E 2017 - IDADE

\begin{tabular}{|l|c|c|c|c|c|}
\hline \multicolumn{1}{|c|}{ ANO/RESULTADOS } & 2013 & 2014 & 2015 & 2016 & 2017 \\
\hline $\begin{array}{l}\% \text { de modelos com idade jovem/ } \\
\text { adulta (entre 18 45 anos) }\end{array}$ & $100 \%$ & $100 \%$ & $99,7 \%$ & $99,96 \%$ & $99 \%$ \\
\hline $\begin{array}{l}\% \text { de modelos com idade adulta/ } \\
\text { madura ou terceira idade (acima } \\
\text { de 46 anos) }\end{array}$ & $0 \%$ & $0 \%$ & $0,3 \%$ & $0,04 \%$ & $1 \%$ \\
\hline
\end{tabular}

FONTE: As autoras, 2017, com base nas referências indicadas na nota 3.

QUADRO 4 - PERFIL DE MODELOS PARTICIPANTES DA SPFW ENTRE 2013 E 2017 - CORPO

\begin{tabular}{|l|c|c|c|c|c|}
\hline \multicolumn{1}{|c|}{ ANO/RESULTADOS } & 2013 & 2014 & 2015 & 2016 & 2017 \\
\hline \% de modelos com corpo magro & $100 \%$ & $100 \%$ & $99,96 \%$ & $99 \%$ & $98,4 \%$ \\
\hline $\begin{array}{l}\% \text { de modelos com corpo } \\
\text { mediano }\end{array}$ & $0 \%$ & $0 \%$ & $0 \%$ & $0,9 \%$ & $1,2 \%$ \\
\hline$\%$ de modelos com corpo gordo & $0 \%$ & $0 \%$ & $0,04 \%$ & $0,1 \%$ & $0,4 \%$ \\
\hline
\end{tabular}

FONTE: As autoras, 2017, com base nas referências indicadas na nota 3.

É interessante constatar que, no período pesquisado, a maioria dos(as) modelos com perfil de beleza fora do padrão era homem, revelando que o modelo consolidado de beleza ainda recaiu de forma mais latente no corpo feminino. Também que, quando havia a presença de modelos fora do arquétipo tradicional, como modelos transgêneros(as), por exemplo, 
a marca ou estilista defendia em sua proposta de coleção questões correlacionadas, como diversidade de gênero, a tolerância da diferença etc. Isto é, a apresentação de corpos distintos precisava ser justificada por um tema de coleção ou por uma "bandeira política”, publicitária, que explicava as escolhas.

Nesse sentido, é possível observar que a escolha de modelos para os desfiles permaneceu conservando uma estrutura bem consolidada quanto a padrão de beleza. E, quando esse comportamento foi diverso, em poucos episódios, demonstrava a busca dos(as) estilistas e das marcas por atenderem, especialmente, as demandas comportamentais de consumidores(as) de suas coleções, em prol de seus negócios. Mesmo assim, não se pode desconsiderar a postura de tais estilistas e marcas, que iam à contramão de uma cultura muito enraizada nesse contexto, que privilegiava e privilegia o corpo mais jovem, magro, alto e branco.

Ao considerar o período estudado como um todo, foi constatado que o percentual de aparições de modelos brancas(os) ou pardas(os) em todas as edições do evento correspondeu a 89,7\%, enquanto foram 9,9\% de modelos pretos(as), 0,4\% de modelos de cor amarela (origem nipônica) e nenhum(a) modelo de cor vermelha (origem indígena). Entre eles(as), participaram 99,7\% com idade entre 18 e 45 anos e 0,3\% com faixa etária superior a 46 anos, bem como 99,4\% de magros(as), 0,5\% com corpos medianos e 0,1\% de gordos(as).

\section{Considerações finais}

Os resultados provenientes do levantamento dos dados das aparições de estilistas e modelos no evento SPFW permitiram compreender parte das configurações e propostas da moda brasileira com relação ao corpo entre os anos 2013 e 2017. De acordo com estes dados, é possível afirmar que o funcionamento da moda brasileira, representada aqui pelo lócus do São Paulo Fashion Week, privilegia majoritariamente corpos brancos, magros, jovens/adultos, o que salienta a manutenção de um padrão estético de beleza reforçado pela moda por diversas décadas.

Em matéria para o jornal O Estado de São Paulo, Brooke Erin Duffy, professora americana da Universidade de Cornell, especializada em estudos sobre mídia e cultura de consumo, afirmou que o padrão de corpo/beleza idealizado na moda "geralmente é alto, branco, magro e com porte aristocrático" (MARTIN, 2016). Esse ideal se difundiu nos anos 1920, momento em que a cultura de consumo americana e o ramo de modelos cresceram simultaneamente, instituindo esse perfil como o adequado. No contexto atual, a beleza constitui uma forma de aceitação social, qualidades estéticas explicitadas nos atributos físicos que são constantemente veiculados pela mídia. 0 corpo é, então, um produto cultural, histórico e social que se fragmentou e se recompôs (DEL PRIORE, 2000) ao longo do tempo, moldando-se a variadas modas.

O grau de diversidade dos perfis de estilistas e modelos investigados foi ínfimo, predominando o biótipo branco, magro e de idade jovem/adulta. Essa constatação revelou que a $S P F W$, enquanto expressão importante do Brasil para o mundo por meio da moda, não representa a multiplicidade de corpos presentes no país. Contrapondo os percentuais obtidos nessa pesquisa aos dados do IBGE de 2016 quanto à cor/etnia, por exemplo - que aponta- 
ram que há no Brasil uma população de 54,9\% de negros e pardos, e 44,2\% de brancos -, a discrepância é latente. E quando a análise se volta aos parâmetros de dimensão física/ biótipo, o corpo magro e jovem/adulto predomina em detrimento do físico gordo e adulto/ maduro ou de terceira idade, e a recusa destes corpos também se apresenta no cenário da moda exposta no evento (SARAIVA, 2017).

As práticas são fruto de representações, amparadas no poder simbólico construído por um determinado grupo e em um determinado tempo histórico e espaço social, estruturados por reproduções de papéis sociais considerados importantes ao longo da história, e que são reforçados pelas práticas dos agentes de poder desse espaço (MARTINS, 2015). Não se pode perder de vista que o São Paulo Fashion Week é um evento com fins comerciais, de promoção das marcas ali apresentadas em busca de imagem positiva que se converta em vendas. Também, que parte das estratégias do evento não só buscava estar em sintonia com perspectivas internacionais como refletia um padrão recorrente em outras fashion weeks e mídias de moda, principalmente a impressa, sob a eficácia das revistas. Novelli (2014), em seu estudo sobre a "branquidade" dominante presente nas revistas Vogue Brasil e Vogue Paris no século XXI, deixa evidente que esse padrão corporal (inter)nacional é uma cultura ainda muito enraizada no campo da moda.

Nessa perspectiva, o corpo dos(as) modelos, em especial, é mais um artifício que o mercado utiliza para impulsionar o consumo, isto é, o corpo que "serve" à moda necessita se moldar as preferências instituídas. Assim, entendendo o papel da moda como orquestradora de condutas a serem copiadas e seguidas, esse corpo da moda apresentado na SPFW, por sua vez, torna-se o corpo desejado que, segundo Mesquita e Castilho (2012), incita a padronização e o culto de um ideal, causando uma influência negativa naqueles que são impactados pela sedução que as imagens promovem, e que em boa parte das vezes não conseguem alcançá-las.

A aparência, então, pode ser entendida como uma característica de nivelamento social. Estilistas seguem ideias dominantes, bem como impõem (de cima pra baixo) esse padrão. A moda, como um dos universos do belo, age como "curadora" da entrada daqueles(as) tidos(as) como detentores(as) de uma estética privilegiada, que atende aos critérios do belo instituídos. É a estética definindo grupos e posicionamentos.

A cultura de valorização do corpo é um fato na sociedade contemporânea. No Brasil, segundo Goldenberg (2007), o corpo constitui-se como um dos capitais (físico, simbólico, social) centrais da cultura, identificando e distinguindo os sujeitos, sendo objeto de desejo, expressão e admiração. "O corpo, muito mais do que as roupas, se transforma em símbolo que consagra e torna evidentes as diferenças entre classes sociais" (GOLDENBERG, 2007, p. 103). Para Samarão (2017, p. 50), “o século XXI traz a obsessão por ser magro, por ter um corpo musculoso, 'perfeito', isento de qualquer descuido ou preguiça [...], à prova de velhice, um corpo que se torna, cada vez mais, um objeto de design”.

Tal afirmação se mostra congruente com os resultados apresentados nesse artigo, pois o ser humano molda sua corporeidade com símbolos que ele sabe que os outros de 
sua sociedade saberão ler, conformando uma construção visual frente a grupos que almeja pertencer, passando por preceitos morais e estéticos, tradicionais ou não, que influem em suas ações (SANTAELLA, 2004). No caso dos corpos presentes no evento SPFW, sejam de estilistas, sejam de modelos escolhidos(as) por eles(as), foi comunicada a continuidade de um arquétipo tradicional e predileto da moda. Os mesmos valores culturais que influem nas escolhas dos(as) modelos agem sobre aqueles(as) que os(as) escolhem, os(as) estilistas.

Ainda, a moda, por estar carregada de códigos e ser um meio de expressão individual e coletiva, tornou-se importante na disseminação de vertentes do comportamento da sociedade, por motivos ideológicos e/ou por interesses econômicos (LIPOVETSKY, 1989). Portanto, refletindo sobre o corpo expresso nas manifestações da SPFW, objeto deste estudo, a afirmação que deu título a esse texto se confirma: "a moda brasileira é jovem, branca e magra". Por meio dos corpos presentes no evento, sejam os de estilistas, sejam os de modelos escolhidos(as) por eles(as), foi comunicada a continuidade de um arquétipo corpóreo tradicional nas aparições de moda, benquisto por seus agentes.

Diante desse cenário, a expectativa que se insere é de que transformações ocorram, tanto no evento São Paulo Fashion Week quanto em outras áreas do "mundo fashion", tornando a moda brasileira, em termos de corpos, mais representativa de toda sua heterogeneidade.

\section{Referências}

ALÁRIO, Mônica Agda de Souza. Os estilistas e a produção de moda. 2007. Tese (Doutorado em Sociologia) - Universidade Estadual Paulista, Faculdade de Ciências e Letras, Araraquara, 2007. Disponível em: https://repositorio.unesp.br/bitstream/handle/11449/106287/alario_mas_dr_ arafcl.pdf?sequence=1. Acesso em: 2 jan. 2018.

BARTHES, Roland. Sistema da moda. Tradução Ivone Castilho Benedetti.1. ed. São Paulo: Martins Fontes, 2009.

BARNARD, Malcolm. Moda e comunicação. Tradução Lúcia Olinto. 1. ed. Rio de Janeiro: Rocco, 2003.

BONADIO, Maria Claudia. Moda e publicidade no Brasil nos anos 1960. 1. ed. São Paulo: Versos, 2014.

BOURDIEU, Pierre. 0 poder simbólico. Tradução Fernando Tomaz. Rio de Janeiro: Bertrand Brasil, 1992.

BOURDIEU, Pierre. Razões práticas: sobre a teoria da ação. Tradução Mariza Corrêa. 11. ed. Campinas: Papirus, 1996. 
BOURDIEU, Pierre. Meditações pascalianas. Tradução Sergio Miceli. Rio de Janeiro: Bertrand Brasil, 2001.

BOURDIEU, Pierre. 0 costureiro e sua grife - contribuição para uma teoria da magia. In: A produção da crença: contribuição para uma economia dos bens simbólicos. Tradução Guilherme João de Freitas Teixeira e Maria da Graça Jacintho Setton. São Paulo: Zouk, 2006.

BRAGA, João; PRADO, Luís André do. História da moda no Brasil - das influências às autorreferências. 2. ed. São Paulo: Disal, 2011.

BRASIL. Lei no 8.069, de 13 de julho de 1990. Dispõe sobre o Estatuto da Criança e do Adolescente e dá outras providências. Brasília: Presidência da República, 1990. Disponível em: http://www.planalto.gov.br/ccivil_03/leis/18069.htm. Acesso em: 13 fev. 2018.

BRASIL. Lei no 10.741, de 1 de outubro de 2003. Dispõe sobre o Estatuto do Idoso e dá outras providências. Brasília: Presidência da República, 2003. Disponível em: http://www. planalto.gov.br/ccivil_03/leis/2003/110.741.htm. Acesso em: 13 fev. 2018.

BRUNA, Maria Helena Varella.Vitiligo. Drauzio Varella.Disponível em: https://drauziovarella. uol.com.br/doencas-e-sintomas/vitiligo/. Acesso em: jul. 2018.

CADDAH, Sergio. SPFW começa com transmissão ao vivo no FFW: saiba tudo aqui. Fashion Forward, 19 jan. 2012. Disponível em: http://ffw.uol.com.br/noticias/moda/a-spfw-vemai-veja-o-line-up-completo-da-edicao-inverno-2012/. Acesso em: 1 dez. 2017.

CAMELO, Priscila. M.; COELHO-COSTA, Ewerton R. Semana de Moda e Turismo de Eventos no Brasil. Revista Rosa dos Ventos - Turismo e Hospitalidade, v. 8, n. III, p. 301-310, jul.set., 2016. Disponível em: http://dx.doi.org/10.18226/21789061.v8i3p301. Acesso em: 1 dez. 2017.

CHLAMTAC, Alexia. A história do SPFW e o crescimento da moda brasileira. Costanza Who?, 14 out. 2015. Disponível em: http://costanzawho.com.br/historia-da-moda/historia-dospfw/. Acesso em: 2 dez. 2017.

DEL PRIORE, Mary. Corpo a corpo com a mulher: pequena história das transformações do corpo feminino no Brasil. 2. ed. São Paulo: SENAC, 2000.

DINIZ, Pedro. Moda celebra 20 anos da SPFW em temporada de mudança. Folha de S. Paulo, 7 nov. 2014. Ilustrada. Disponível em: http://www1.folha.uol.com.br/ ilustrada/2014/11/1544292-moda-celebra-20-anos-da-spfw-em-temporada-demudanca.shtml. Acesso em: 1 nov. 2017. 
FASHION FORWARD. 2018. Disponível em: http://ffw.uol.com.br. Acesso em: 1 fev. 2018.

FORMIGA, Isabella. Excesso de peso atinge 52,5\% dos brasileiros, segundo pesquisa Vigitel. G1, 15 abr. 2015. Bem Estar. Disponível em: http://g1.globo.com/bemestar/ noticia/2015/04/excesso-de-peso-atinge-525-dos-brasileiros-segundo-pesquisa-vigitel. html. Acesso em: 29 jan. 2018.

GOLDENBERG, Mirian. 0 corpo como capital. São Paulo: Estação das Letras e Cores, 2007.

GUERATO, Ariane Magalhães. Turismo e consumo: um estudo da SPFW. 2010. Trabalho de Conclusão de Curso (Graduação em Turismo) - Universidade Federal de São Carlos, Sorocaba, 2010.

IEMI - Instituto de Estudos e Marketing Industrial. Estudo da competitividade do setor do vestuário no estado do Paraná: relatório setorial, 2013.

KISS, Maria Augusta Peduti Dalmolin. Avaliação em educação física: aspectos biológicos e educacionais. São Paulo: Manole, 1987.

LIPOVETSKY, Gilles. 0 império do efêmero: a moda e seu destino nas sociedades modernas. Tradução Maria Lúcia Machado. São Paulo: Companhia das Letras, 1989.

MARTIN, Crystal. Por que a indústria de beleza ignora as modelos plus size? 0 Estado de São Paulo, 22 jul. 2016. Emais. Disponível em: http://emais.estadao.com.br/noticias/ moda-beleza,por-que-a-industria-de-beleza-ignora-as-modelos-plus-size,10000064377. Acesso em: 20 jan. 2018.

MARTINS, Ana Caroline. Siqueira. “A nossa diferença é a criatividade!”: A configuração do setor industrial de moda em Cianorte/PR. 2015. Dissertação (Mestrado em Ciências Sociais) - Universidade Estadual do Oeste do Paraná, Toledo, 2015. Disponível em: http:// tede.unioeste.br/bitstream/tede/2022/1/Ana\%20C\%20Siqueira\%20Martins.pdf. Acesso em: 9 maio 2019.

MESQUITA, Cristiane.; CASTILHO, Kathia. Corpo, moda e ética: pistas para uma reflexão de valores. 2. ed. São Paulo: Estação das Letras e Cores, 2012.

NOVELLI, Daniela. A branquidade em Vogue (Paris e Brasil): imagens da violência simbólica no séculoXXI. 2014. Tese (Doutorado em Ciências Humanas) - Universidade Federal de Santa Catarina, Centro de Filosofia e Ciências Humanas, Florianópolis, 2014. Disponível em: https://repositorio.ufsc.br/xmlui/bitstream/handle/123456789/123183/327370. pdf?sequence=1\&isAllowed=y. Acesso em: 7 maio 2019. 
PNAD 2016: população idosa cresce 16,0\% frente a 2012 e chega a 29,6 milhões. Agência IBGE, 24 nov. 2017. Estatísticas Sociais. Disponível em: https://agenciadenoticias.ibge.gov.br/ agencia-sala-de-imprensa/2013-agencia-de-noticias/releases/18263-pnad-2016-populacaoidosa-cresce-16-0-frente-a-2012-e-chega-a-29-6-milhoes. Acesso em: 20 jun. 2018.

SABINO, Marcos. Ectomorfo, mesomorfo, endomorfo: qual o meu somatotipo corporal? Tá fitness, 2 jul. 2017. Disponível em: http://tafitness.net/ectomorfo-mesomorfo-endomorfosomatotipo-corporal/. Acesso em: 4 mai. 2019.

SAMARÃO, Liliany. 0 espetáculo da publicidade: a representação do corpo feminino na mídia. Contemporânea UERJ, n. 8, p. 45-57, 2007. Disponível em: http://www.contemporanea. uerj.br/pdf/ed_08/04LILIANY.pdf. Acesso em: 2 jul. 2019.

SANTAELLA, Lucia. Corpo e comunicação: sintoma da cultura. 1. ed. São Paulo: Paulus, 2004.

SARAIVA, Adriana. População chega a 205,5 milhões, com menos brancos e mais pardos e pretos. Agência IBGE, 24 nov.2017.Estatísticas Sociais. Disponível em: https://agenciadenoticias.ibge. gov.br/agencia-noticias/2012-agencia-de-noticias/noticias/18282-pnad-c-moradores. html. Acesso em: 22 jan. 2018. 